\title{
Alanine aminotransferase/aspartate aminotransferase ratio is the best surrogate marker for insulin resistance in non-obese Japanese adults
}

\author{
Ryuichi Kawamoto ${ }^{1,4^{*}}$, Katsuhiko Kohara ${ }^{2}$, Tomo Kusunoki ${ }^{1}$, Yasuharu Tabara ${ }^{3}$, Masanori Abe ${ }^{1}$ and Tetsuro Miki ${ }^{2}$
}

\begin{abstract}
Background: The aim of the present study was to examine how liver markers are associated with insulin resistance in Japanese community-dwelling adults.

Methods: This cross-sectional study included 587 men aged $58 \pm 14$ (mean \pm standard deviation; range, 20-89) years and 755 women aged $60 \pm 12$ (range, 21-88) years. The study sample consisted of 998 (74.4\%) non-obese [body mass index (BMI) $<25.0 \mathrm{~kg} / \mathrm{m}^{2}$ ] and $344(25.6 \%)$ overweight $\left(\mathrm{BMI} \geq 25 \mathrm{~kg} / \mathrm{m}^{2}\right)$ subjects. Insulin resistance was defined by homeostasis model assessment of insulin resistance (HOMA-IR) of at least 2.5, and HOMA-IR and potential confounders were compared between the groups. Areas under the curve (AUC) of the receiver operating characteristic curves (ROC) were used to compare the power of these serum markers.

Results: In non-obese subjects, the best marker of insulin resistance was alanine aminotransferase (ALT)/aspartate aminotransferase (AST) ratio of 0.70 (95\% confidence interval (CI), 0.63-0.77). In overweight subjects, AUC values for the ALT/AST ratio and ALT were 0.66 (0.59-0.72) and 0.66 (0.59-0.72), respectively. Multiple linear regression analyses for HOMA-IR showed that ALT/AST ratios were independently and significantly associated with HOMA-IR as well as other confounding factors in both non-obese and overweight subjects. The optimal cut-off point to identifying insulin resistance for these markers yielded the following values: ALT/AST ratio of $\geq 0.82$ in non-obese subjects and $\geq 1.02$ in overweight subjects. In non-obese subjects, the positive likelihood ratio was greatest for ALT/AST ratio.
\end{abstract}

Conclusions: In non-obese Japanese adults, ALT/AST ratio may be the best reliable marker of insulin resistance.

Keywords: ALT/AST ratio, Insulin resistance, Marker, Body mass index

\section{Background}

Obesity is also a major worldwide public health problem and is associated with a high risk of developing insulin resistance [1]. Insulin resistance plays an important role in the pathogenesis of incident diabetes, hypertension, dyslipidemia, and cardiovascular disease (CVD) [2-4]. Detailed measurement of insulin resistance requires the use of diffuse techniques (e.g., glucose clamp technique.)

\footnotetext{
* Correspondence: rykawamo@m.ehime-u.ac.jp

${ }^{1}$ Department of Community Medicine, Ehime University Graduate School of

Medicine, Toon-city, Ehime, Japan

${ }^{4}$ Department of Internal Medicine, Seiyo Municipal Nomura Hospital,

Seiyo-city, Ehime 797-1212, Japan

Full list of author information is available at the end of the article
}

that require expense and time. Alternatives have been sought to simplify the measurement of insulin resistance and one is Homeostatic Model Assessment of insulin resistance (HOMA-IR), which uses fasting insulin and glucose levels to calculate insulin resistance [5] and correlates reasonably with the results of clamping studies. The use of this index is problematic, however, in that insulin levels are not measured during the usual annual health examination and in clinical practice.

Many studies have demonstrated that alanine aminotransferase (ALT), aspartate aminotransferase (AST) and gammaglutamyl transferase (GGT) levels independently predict type 2 diabetes [6-10], metabolic syndrome [11-14], and CVD [8]. These markers have been shown to be associated with

\section{Biomed Central}


indirect measurements of insulin resistance including fasting insulin levels [14] and HOMA-IR [10,15-17]. However, in Japanese community-dwelling persons, there are few studies to demonstrate a relationship between liver markers and insulin resistance, categorized by BMI. It is important for us to be able to evaluate insulin resistance by measuring the liver markers which are inexpensive and routinely measured in clinical setting.

We took advantage of the large representative sample of Japanese adults who participated at the time of their annual health examination. We investigated how liver markers were associated with insulin resistance in healthy Japanese adults. For this, we used cross-sectional data from community-dwelling participants without clinical diabetes.

\section{Methods}

\section{Subjects}

The present study is designed as a part of the Nomura study [18]. Subjects were selected through a communitybased annual check-up process in a rural town located in Ehime prefecture, Japan. A sample of 3,164 subjects was recruited and the available sample population compromised 2,764 subjects. Information on medical history, present conditions, and drugs was obtained by interview. Other characteristics, such as smoking and alcohol habits, and medication, were investigated by individual interviews using a structured questionnaire. Subjects taking medications for hypertension $(\mathrm{N}=736)$, diabetes $(\mathrm{N}=153)$, or dyslipidemia $(\mathrm{N}=108)$ were excluded $(\mathrm{N}=877)$. For all these individuals, overnight fasting plasma samples were available for measuring immunoreactive insulin (IRI) and high sensitivity C-reactive protein (hsCRP). We reduced the number of subjects $(\mathrm{N}=545)$ because the omitted subjects' samples had a limited volume of plasma. The final study sample included 1,342 eligible persons. The final study sample included 587 men and 755 women. This study was approved by the ethics committee of Ehime University School of Medicine, and written informed consent was obtained from each subject.

\section{Evaluation of confounding factors}

Information on demographic characteristics and risk factors was collected using clinical files. Body mass index was calculated by dividing weight (in kilograms) by the square of the height (in meters). Smoking status was defined as the number of cigarette packs per day multiplied by the number of years smoked (pack·year), and the participants were classified into never smokers, past smokers, light smokers ( $<30$ pack·year) and heavy smokers ( $\geq 30$ pack; year). The daily alcohol consumption was measured using the Japanese liquor unit in which a unit corresponds to $22.9 \mathrm{~g}$ of ethanol, and the participants were classified into never drinkers, occasional drinkers ( $<1$ unit/day), light drinkers (1-1.9 unit/day), and heavy drinkers ( $\geq 2$ unit/ day). We measured blood pressure in the right upper arm of the participants in a sedentary position using an automatic oscillometric blood pressure recorder (BP-103i; Colin, Aichi, Japan) while the subjects were seated after having rested for at least $5 \mathrm{~min}$. Total cholesterol (T-C), triglycerides (TG), high-density lipoprotein cholesterol (HDL-C), fasting plasma glucose (FPG), uric acid, hsCRP, high molecular weight (HMW) adiponectin (FUJIREBIO, Tokyo, Japan), GGT, ALT, AST, and IRI were measured during fasting. Low-density lipoprotein cholesterol (LDL-C) levels were calculated using the Friedewald formula [19]. Participants with TG levels $\geq 400 \mathrm{mg} / \mathrm{dl}$ were excluded. HOMA-IR was calculated from FPG and IRI levels using the following formula; [FPG $(\mathrm{mg} / \mathrm{dL}) \mathrm{X}$ IRI $(\mathrm{mU} / \mathrm{mL})] / 405$ [5], and a level of Insulin resistance was defined as HOMA-IR $\geq 2.5$ [5].

\section{Statistical analysis}

Statistical analysis was performed using IBM SPSS Statistics Version 20 (Statistical Package for Social Science Japan, Inc., Tokyo, Japan). All values are expressed as mean \pm standard deviation (SD), unless otherwise specified. Data for TG, hsCRP, serum HMW adiponectin, GGT, ALT, and AST were skewed, and are presented as median (interquartile range) values, and were log-transformed for analysis. Subjects were divided into two groups based on BMI [nonobese, $<25.0 \mathrm{~kg} / \mathrm{m}^{2}$; overweight, $\geq 25.0 \mathrm{~kg} / \mathrm{m}^{2}$ (waist circumference was not available in this study)], and differences between the two groups were determined by Student's ttest and $\chi^{2}$ test. In addition, areas under the receiver operating characteristic (ROC) curves were determined for each variable to identify the predictors of insulin resistance. Areas under the ROC curves are provided with standard errors. An ROC curve is a plot of the sensitivity (true positive) versus 1-specificity (false positive) for each potential marker tested. The area under the ROC curve is a summary of the overall diagnostic accuracy of the test. The best markers have ROC curves that are shifted to the left with areas under the curve near unity. Nondiagnostic markers are represented by diagonals with areas under the ROC curves close to 0.5 . Likelihood ratios were calculated as the ratios of sensitivity/(1-specificity) (positive likelihood ratio) and (1-sensitivity)/specificity (negative likelihood ratio). Multiple linear regression analysis was used to evaluate the contribution of each confounding factor for HOMA-IR. A value of $P<0.05$ was considered significant.

\section{Results}

\section{Background factors of subjects categorized by BMI}

Table 1 shows the value of each background factor categorized by BMI. The subjects comprised 587 men aged $58 \pm 14$ (range, 20-89) years and 755 women aged $60 \pm 12$ (range, 21-88) years. The mean BMI in 
Table 1 Characteristics of subjects categorized by body mass index

\begin{tabular}{|c|c|c|c|c|}
\hline \multirow[t]{2}{*}{ Body mass indext characteristics } & \multirow{2}{*}{$\begin{array}{c}\text { Total } \\
\text { All } N=1,342\end{array}$} & \multirow{2}{*}{$\frac{\text { Non-obese }}{<25.0 \mathrm{~kg} / \mathrm{m}^{2} \mathrm{~N}=998}$} & \multirow{2}{*}{$\frac{\text { Overweight }}{\geq 25.0 \mathrm{~kg} / \mathrm{m}^{2} \mathrm{~N}=344}$} & \multirow[t]{2}{*}{$P$-value* } \\
\hline & & & & \\
\hline Male sex, $\%$ & 43.7 & 42.8 & 46.5 & 0.232 \\
\hline Age (years) & $59 \pm 13$ & $60 \pm 13$ & $57 \pm 12$ & 0.012 \\
\hline Body mass index $\left(\mathrm{kg} / \mathrm{m}^{2}\right)$ & $23.1 \pm 3.1$ & $21.7 \pm 2.0$ & $27.1 \pm 2.2$ & $<0.001$ \\
\hline Smoking status \{never/ex/light/heavy (\%)\} & 71.2/9.6/9.1/10.1 & 72.6/8.3/8.9/10.1 & $66.9 / 13.4 / 9.6 / 10.2$ & 0.043 \\
\hline Alcohol consumption \{never/light/moderate/heavy (\%)\} & $38.8 / 31.8 / 18.6 / 10.8$ & $40.5 / 30.5 / 18.9 / 10.1$ & 34.0/35.8/17.4/12.8 & 0.072 \\
\hline Cardiovascular disease, $\%$ & 4.5 & 4.7 & 4.1 & 0.764 \\
\hline Systolic blood pressure $(\mathrm{mmHg})$ & $134 \pm 21$ & $132 \pm 21$ & $139 \pm 19$ & $<0.001$ \\
\hline Diastolic blood pressure (mmHg) & $80 \pm 11$ & $79 \pm 11$ & $84 \pm 10$ & $<0.001$ \\
\hline Total cholesterol (mg/dL) & $201 \pm 35$ & $200 \pm 34$ & $205 \pm 35$ & 0.024 \\
\hline Triglycerides (mg/dL) & $90(67-126)$ & $85(64-117)$ & $108(81-152)$ & $<0.001$ \\
\hline HDL cholesterol (mg/dL) & $63 \pm 15$ & $65 \pm 16$ & $57 \pm 13$ & $<0.001$ \\
\hline LDL cholesterol (mg/dL) & $118 \pm 32$ & $116 \pm 31$ & $123 \pm 32$ & $<0.001$ \\
\hline Uric acid (mg/dL) & $5.0 \pm 1.4$ & $4.8 \pm 1.4$ & $5.5 \pm 1.4$ & $<0.001$ \\
\hline High sensitivity CRP (mg/dL) & $0.04(0.02-0.09)$ & $0.04(0.02-0.07)$ & $0.07(0.04-0.15)$ & $<0.001$ \\
\hline Serum HMW adiponectin $(\mu \mathrm{g} / \mathrm{mL})$ & $4.89(2.98-7.99)$ & $5.37(3.21-8.69)$ & $3.95(2.24-5.82)$ & $<0.001$ \\
\hline GGT (IU/L) & $25(18-43)$ & $22[17-37]$ & $32(21-63)$ & $<0.001$ \\
\hline ALT (IU/L) & 17 [13-24] & $16[12-21]$ & $22[16-31]$ & $<0.001$ \\
\hline AST (IU/L) & $21[18-26]$ & $21[18-26]$ & 22 [19-27] & 0.013 \\
\hline ALT/AST ratio & $0.79(0.65-1.0)$ & $0.74(0.63-0.91)$ & $0.96(0.72-1.2)$ & $<0.001$ \\
\hline
\end{tabular}

$\mathrm{HDL}$, high-density lipoprotein; LDL, low-density lipoprotein; CRP; C-reactive protein; HMW, high molecular weight; GGT, Gamma-glutamyl transferase; ALT, alanine aminotransferase; AST, aspartate aminotransferase. Data presented are mean \pm standard deviation. Data for triglycerides, high sensitivity CRP, serum HMW adiponectin, GGT, ALT, AST, and ALT/AST ratio were skewed, and are presented as median (interquartile range), and were log-transformed for analysis. * Student's t-test or $\mathrm{X}^{2}$ test.

the study sample was $23.1 \pm 3.1 \mathrm{~kg} / \mathrm{m}^{2}$, with 998 (74.4\%) non-obese (BMI $\left.<25.0 \mathrm{~kg} / \mathrm{m}^{2}\right)$ and 344 (25.6\%) overweight (BMI $\left.\geq 25 \mathrm{~kg} / \mathrm{m}^{2}\right)$. Prevalence of smoker, systolic blood pressure (SBP), diastolic blood pressure (DBP), T-C, TG, LDL-C, uric acid, hsCRP, GGT, ALT, AST, and ALT/AST ratio were significantly higher in subjects with a BMI $\geq 25.0 \mathrm{~kg} / \mathrm{m}^{2}$, but age, HDL-C and serum HMW adiponectin were significantly lower in that group. There were no inter- group differences in sex, alcohol consumption, and prevalence of CVD.

\section{Insulin resistance of subjects categorized by $\mathrm{BMI}$}

FBG, IRI, and HOMA-IR were significantly higher in overweight subjects (Table 2), and prevalence of insulin resistance (HOMA-IR $\geq 1.6$ or $\geq 2.5$ ) was significantly higher in overweight subjects than in non-obese subjects.

Table 2 Insulin resistance of subjects categorized by body mass index

\begin{tabular}{|c|c|c|c|c|}
\hline \multirow[t]{2}{*}{ Body mass index characteristics } & \multirow{2}{*}{$\frac{\text { Total }}{\text { All } N=1,342}$} & \multirow{2}{*}{$\frac{\text { Non-obese }}{<25.0 \mathrm{~kg} / \mathrm{m}^{2} \mathrm{~N}=998}$} & \multirow{2}{*}{$\frac{\text { Overweight }}{\geq 25.0 \mathrm{~kg} / \mathrm{m}^{2} \mathrm{~N}=344}$} & \multirow[t]{2}{*}{$P$-value } \\
\hline & & & & \\
\hline Fasting blood glucose (mg/dL) & $92(87-99)$ & $91(86-98)$ & $96(89-103)$ & $<0.001$ \\
\hline Immunoreactive insulin (mU/mL) & $5.2(3.4-7.7)$ & $4.5(3.0-6.6)$ & $8.0(5.4-11.2)$ & $<0.001$ \\
\hline HOMA-IR + & $1.20(0.76-1.84)$ & $1.03(0.67-1.54)$ & $1.93(1.23-2.81)$ & $<0.001$ \\
\hline HOMA-IRt $<1.6, \%$ & 67.5 & 77.5 & 38.7 & \\
\hline HOMA-IRt $\geq 1.6$ and $<2.5, \%$ & 20.0 & 16.3 & 30.8 & $<0.001$ \\
\hline HOMA-IR $\dagger \geq 2.5, \%$ & 12.4 & 6.2 & 30.5 & $<0.001$ \\
\hline
\end{tabular}

HOMA-IR, homeostasis of minimal assessment of insulin resistance. Data for fasting blood glucose, fasting immunoreactive insulin, and HOMA-IR were skewed, and are presented as median (interquartile range). HHOMA-IR was calculated using the following formula; [fasting blood glucose (FBG) (mg/dL) X fasting Immunoreactive insulin ( $\mathrm{mU} / \mathrm{mL})] / 405$. Data for fasting blood glucose, Immunoreactive insulin, and HOMA-IR were log-transformed for analysis. *Student's t test or $x^{2}$ test. 
Table 3 Comparison of areas under the ROC curves $(95 \% \mathrm{CI})$ for potential markers of insulin resistance (HOMA-IR $\geq 2.5)$ of subjects categorized by body mass index

\begin{tabular}{|c|c|c|c|c|c|c|}
\hline \multirow{3}{*}{ Body mass index characteristics } & \multicolumn{6}{|c|}{ AUC $(95 \% \mathrm{Cl})$} \\
\hline & Total & $P$-value & Non-obese & $P$-value & Overweight & $P$-value \\
\hline & $\overline{\text { All } N=1,342}$ & & $<25.0 \mathrm{~kg} / \mathrm{m}^{2} \mathrm{~N}=998$ & & $\geq 25.0 \mathrm{~kg} / \mathrm{m}^{2} \mathrm{~N}=344$ & \\
\hline Triglycerides (mg/dL) & $0.69(0.65-0.73)$ & $<0.001$ & $0.66(0.59-0.73)$ & $<0.001$ & $0.65(0.58-0.71)$ & $<0.001$ \\
\hline High sensitivity CRP (mg/dL) & $0.68(0.64-0.72)$ & $<0.001$ & $0.61(0.55-0.68)$ & 0.003 & $0.63(0.57-0.70)$ & $<0.001$ \\
\hline Serum HMW adiponectin $(\mu \mathrm{g} / \mathrm{mL})$ & $0.32(0.28-0.36)$ & $<0.001$ & $0.32(0.25-0.39)$ & $<0.001$ & $0.40(0.33-0.46)$ & 0.003 \\
\hline GGT (IU/L) & $0.63(0.58-0.67)$ & $<0.001$ & $0.61(0.54-0.67)$ & 0.005 & $0.54(0.48-0.61)$ & 0.211 \\
\hline ALT (IU/L) & $0.69(0.64-0.73)$ & $<0.001$ & $0.62(0.55-0.69)$ & 0.002 & $0.66(0.59-0.72)$ & $<0.001$ \\
\hline AST (IU/L) & $0.56(0.51-0.61)$ & 0.013 & $0.49(0.41-0.57)$ & 0.818 & $0.59(0.52-0.66)$ & 0.007 \\
\hline ALT/AST ratio & $0.74(0.70-0.78)$ & $<0.001$ & $0.70(0.63-0.77)$ & $<0.001$ & $0.66(0.59-0.72)$ & $<0.001$ \\
\hline
\end{tabular}

$\mathrm{ROC}$, receiver operating characteristics; $\mathrm{Cl}$, confidence interval; AUC, area under ROC curve. Data for triglycerides, high sensitivity CRP, serum HMW adiponectin, GGT, ALT, AST, and ALT/AST ratio were skewed and log-transformed for analysis.

Comparison of areas under ROC curves [95\% confidence interval] for potential markers of insulin resistance of subjects categorized by BMI

In non-obese subjects, the ROC curve analyses showed that the best marker of insulin resistance was ALT/AST ratio, with an area under the ROC curve of 0.70 (0.63-0.77) (Table 3; Figure 1). Serum HMW adiponectin, ALT, and hsCRP also discriminated insulin resistance, as they had areas under the ROC curve of 0.32 (0.25-0.39), 0.62 (0.55$0.69)$, and $0.61(0.55-0.68)$, respectively. In overweight subjects, ALT/AST ratio and ALT were more effective.

\section{Relationship between various confounding factors and} HOMA-I of subjects categorized by body mass index Figure 2 shows the relationships between AST/ALT ratio and HOMA-IR. AST/ALT ratio was also significantly associated with measures of HOMA-IR in both non-obese $(\mathrm{r}=0.274, P<0.001)$ and overweight subjects $(\mathrm{r}=0.253$,
$P<0.001)$. To further investigate whether AST/ALT ratio can explain the changes in HOMA-IR levels independent of other known confounding factors, multiple linear regression analyses for HOMA-IR showed that AST/ALT ratio was independently and significantly associated with HOMA-IR in both non-obese $(\beta=0.129, P<0.001)$ and overweight subjects $(\beta=0.143, P=0.038)$ (Table 4$)$.

\section{Optimal cut-off point of ALT/AST ratio for predicting} insulin resistance of subjects categorized by BMI

Table 5 shows the cut-off points of ALT/AST ratio for identifying insulin resistance. The optimal cut-off point to identifying insulin resistance for these markers yielded the following values: ALT/AST ratio of $\geq 0.82$ in nonobese subjects, and $\geq 1.02$ in overweight. In non-obese subjects, the positive likelihood ratio value indicates that the odds of insulin resistance increased by 1.91 -fold if
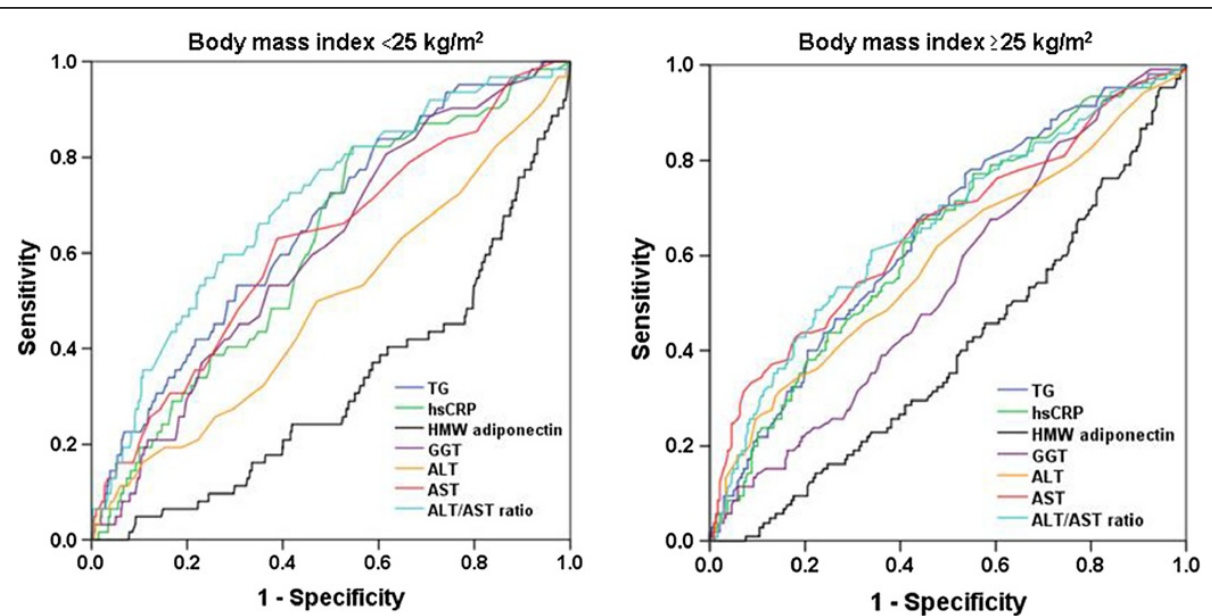

Figure 1 Receiver operating characteristics (ROC) curves. Sensitivity represents the true-positive results and 1-specificity, the false-positive results. The best markers have ROC curves that are shifted to the left with areas under the curve near unity. Nondiagnostic markers are represented by diagonals with areas under the ROC curves close to 0.5 . 


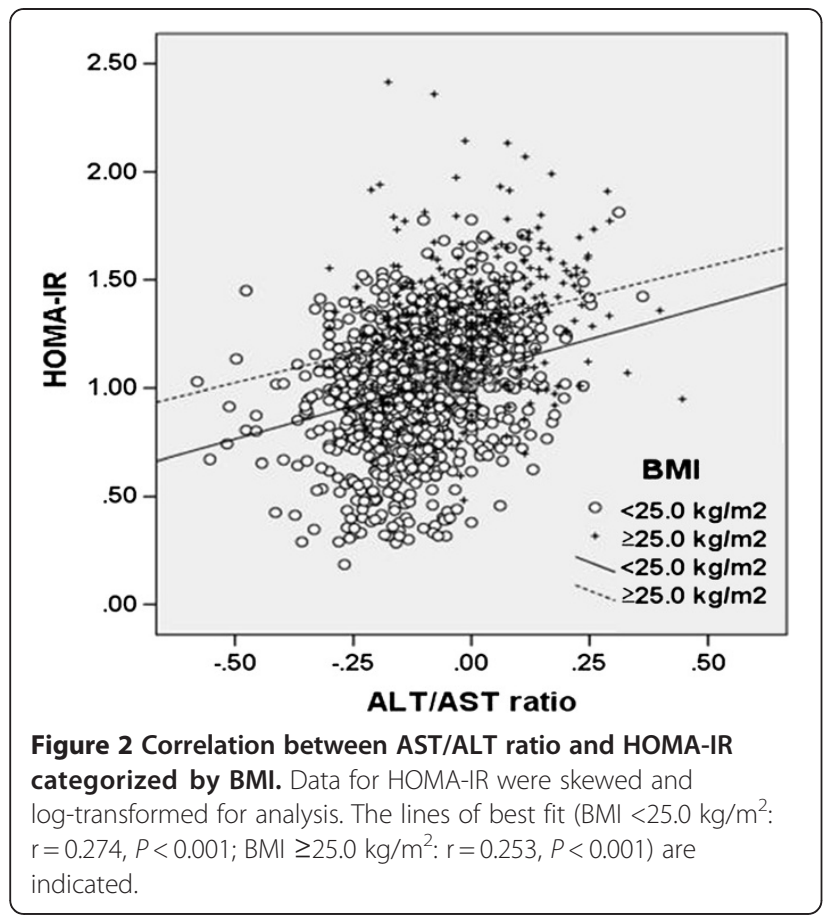

ALT/AST ratio was positive (the value $\geq 0.82$ ). The negative likelihood ratios indicate the extent to which the odds of insulin resistance decrease if the test is negative. These odds also decreased more so for ALT/AST ratio. In overweight subjects, these values were similar.
Relationship between ALT/AST ratio and insulin resistance of subjects within selected subgroups

Next, to control potential confounding by gender and $\mathrm{BMI}$, the data were further stratified by gender and BMI (Table 6). In both genders with a BMI of 22.0 to $25.0 \mathrm{~kg} / \mathrm{m}^{2}$, AST/ALT ratio was a reliable marker of insulin resistance, but in subjects with a BMI of $<22.0 \mathrm{~kg} / \mathrm{m}^{2}$, AST/ALT ratio was not significantly associated with HOMA-IR.

\section{Discussion}

In the present study, we examined whether liver markers (e.g., GGT, ALT, AST, and ALT/AST ratio) as well as gender, age, BMI, smoking status, alcohol consumption, SBP, lipid profiles, uric acid, and serum HMW adiponectin were associated with insulin resistance in Japanese adults, categorized by body mass index. Most fundamental is the fact that not all overweight or obese persons are insulin resistant. In non-obese subjects, $6.2 \%$ of them were insulin resistant, and the best marker of insulin resistance was ALT/AST ratio, but serum HMW adiponectin, ALT, and hsCRP also discriminated insulin resistance. In the overweight subjects, areas of the ALT/AST ratio and ALT were greater than those of the other parameters. The optimal cut-off point to identifying insulin resistance for these markers yielded the following values: ALT/AST ratio of $\geq 0.82$ in the non-obese, and $\geq 1.02$ in the overweight subjects. The positive

Table 4 Multiple linear regression analysis of the correlation between various confounding factors and HOMA-IR of subjects categorized by body mass index

\begin{tabular}{|c|c|c|c|}
\hline \multirow[t]{3}{*}{ Body mass indext characteristics } & \multicolumn{3}{|c|}{$\beta(P$-value $)$} \\
\hline & Total & Non-obese & Overweight \\
\hline & All $N=1,342$ & $\overline{<25.0 \mathrm{~kg} / \mathrm{m}^{2} \mathrm{~N}=998}$ & $\geq 25.0 \mathrm{~kg} / \mathrm{m}^{2} \mathrm{~N}=344$ \\
\hline Male sex,\% & $0.247(<0.001)$ & $0.281(<0.001)$ & $0.219(0.005)$ \\
\hline Age (years) & $-0.064(0.020)$ & $-0.116(0.001)$ & $0.094(0.135)$ \\
\hline Body mass index $\left(\mathrm{kg} / \mathrm{m}^{2}\right)$ & $0.320(<0.001)$ & $0.206(<0.001)$ & $0.262(<0.001)$ \\
\hline Smoking status \{never/ex/light/heavy (\%)\} & $-0.065(0.014)$ & $-0.060(0.075)$ & $-0.103(0.073)$ \\
\hline Alcohol consumption \{never/light/moderate/heavy(\%)\} & $-0.114(<0.001)$ & $-0.137(<0.001)$ & $-0.081(0.222)$ \\
\hline Cardiovascular disease, $\%$ & $0.032(0.140)$ & $0.055(0.046)$ & $-0.024(0.610)$ \\
\hline Systolic blood pressure (mmHg) & $0.093(<0.001)$ & $0.126(<0.001)$ & $0.032(0.543)$ \\
\hline Triglycerides (mg/dL) & $0.138(<0.001)$ & $0.145(<0.001)$ & $0.164(0.005)$ \\
\hline HDL cholesterol (mg/dL) & $-0.033(0.215)$ & $-0.038(0.249)$ & $-0.028(0.645)$ \\
\hline LDL cholesterol (mg/dL) & $0.041(0.079)$ & $0.063(0.034)$ & $0.010(0.848)$ \\
\hline Uric acid (mg/dL) & $0.021(0.451)$ & $0.049(0.153)$ & $-0.052(0.400)$ \\
\hline High sensitivity CRP (mg/dL) & $0.049(0.035)$ & $0.048(0.095)$ & $0.074(0.149)$ \\
\hline Serum HMW adiponectin $(\mu \mathrm{g} / \mathrm{mL})$ & $-0.164(<0.001)$ & $-0.162(<0.001)$ & $-0.231(0.001)$ \\
\hline GGT (IU/L) & $0.097(0.001)$ & $0.079(0.031)$ & $0.149(0.038)$ \\
\hline ALT/AST ratio & $0.122(<0.001)$ & $0.129(<0.001)$ & $0.143(0.038)$ \\
\hline$R^{2}$ & $0.417(<0.001)$ & $0.315(<0.001)$ & $0.290(<0.001)$ \\
\hline
\end{tabular}

Data for triglycerides, high sensitivity CRP, serum HMW adiponectin, GGT, ALT/AST ratio and HOMA-IR were skewed and log-transformed for analysis. 
Table 5 Comparison of ALT/AST ratio for predicting of insulin resistance (HOMA-IR $\geq 2.5$ ) of subjects categorized by body mass index

\begin{tabular}{|c|c|c|c|c|c|c|c|}
\hline \multirow[t]{2}{*}{ Characteristics cut-off point } & \multicolumn{6}{|c|}{ HOMA-IR } & \multirow[b]{2}{*}{ Accuracy } \\
\hline & $<2.5$ & $\geq 2.5$ & Sensitivity & Specificity & Positive LR & $\overline{\text { Negative LR }}$ & \\
\hline Body mass index $<25.0 \mathrm{~kg} / \mathrm{m}^{2}$ & $\mathrm{~N}=936$ & $N=62$ & & & & & $\%$ \\
\hline ALT/AST ratio $<0.82$ & 612 & 22 & 0.67 & 0.65 & 1.91 & 0.51 & 65.3 \\
\hline ALT/AST ratio $\geq 0.82$ & 324 & 40 & & & & & \\
\hline Body mass index $\geq 25.0 \mathrm{~kg} / \mathrm{m}^{2}$ & $N=239$ & $N=105$ & & & & & \\
\hline ALT/AST ratio $<1.02$ & 158 & 41 & 0.66 & 0.61 & 1.69 & 0.56 & 64.5 \\
\hline ALT/AST ratio $\geq 1.02$ & 81 & 64 & & & & & \\
\hline
\end{tabular}

LR, likelihood ratio.

likelihood ratio was greatest for ALT/AST ratio in the non-obese subjects. ALT/AST ratio, an inexpensive and routinely measured clinical variable, might be used as an integrated parameter and measure to evaluate insulin resistance in community-dwelling persons, especially non-obese subjects.

Insulin resistance is common and when clustered with glucose intolerance, dyslipidemia and high blood pressure, and present in type 2 diabetes it play a key role in the occurrence of hyperglycemia. Resistance to insulin-mediated glucose disposal is distributed continuously through the general population [20], and we have no criterion with which to identify a participant as being insulin resistance. However, we classified a participant with a HOMA-IR of $>2.5$ as insulin resistance [21]. Some previous studies have demonstrated that HOMA-IR strongly correlates with glucose clamp-assessed insulin resistance [5,20] and has the advantage of requiring only a single plasma sample assayed for insulin and glucose. However, HOMA-IR is less accurate and precise than the glucose clamp method in measuring insulin resistance, but this limitation is now mitigated, because the HOMA model has become a widely used clinical and epidemiological tool, as in our study $[22,23]$. Thus, we used HOMA-IR as a marker of insulin resistance in this study.

In previous studies, several lipid ratios have been proposed as simple and useful clinical indicators of insulin resistance. The TG/HDL-C, the T-C/HDL-C, and the LDL-C/HDL-C ratio have shown similar potential for insulin resistance, though the reports are not entirely consistent [24-27]. Also in our study, both LDL-C/HDL-C and TG/HDL-C ratio were useful markers of insulin resistance, especially in all subjects or non-obese subjects. However, these markers were weaker in overweight subjects [28]. ALT/AST ratio as well as LDL-C/HDL-C and the TG/HDL-C ratio were also strongly related to insulin resistance. Several studies have reported a significant association of ALT with HOMA-IR [15,29,30]. Moreover, Hanley et al. [30,31] reported that ALT/AST ratio predicts metabolic syndrome independently of potential

Table 6 Association between ALT/AST ratio and insulin resistance (HOMA-IR $\geq 2.5$ ) and HOMA-IR within selected subgroups

\begin{tabular}{|c|c|c|c|c|c|}
\hline \multirow[t]{2}{*}{ Stratified subgroups } & \multirow[t]{2}{*}{$\mathbf{N}$} & \multirow[t]{2}{*}{ HOMA-IR $\geq 2.5, \%$} & \multicolumn{3}{|c|}{ ALT/AST ratio } \\
\hline & & & $\begin{array}{c}\text { ROC curves AUC } \\
(95 \% \mathrm{Cl})\end{array}$ & $\begin{array}{c}\text { BMI-adjusted } \beta \\
(P \text {-value })\end{array}$ & $\begin{array}{c}\text { Multivariate-adjusted } \beta \\
(P \text {-value })\end{array}$ \\
\hline \multicolumn{6}{|c|}{ Men Body mass index $\left(\mathrm{kg} / \mathrm{m}^{2}\right)$} \\
\hline Total & 587 & $66(11.2)$ & $0.75(0.68-0.81$ & $0.253(<0.001)$ & $0.104(0.016)$ \\
\hline$<22.0$ & 202 & $7(3.5)$ & $0.67(0.44-0.89)$ & $0.257(<0.001)$ & $0.141(0.051)$ \\
\hline $22.0-25.0$ & 225 & $19(8.4)$ & $0.64(0.51-0.77)$ & $0.317(<0.001)$ & $0.166(0.030)$ \\
\hline$<25.0$ & 427 & $26(6.1)$ & $0.67(0.56-0.77)$ & $0.274(<0.001)$ & $0.143(0.004)$ \\
\hline$\geq 25.0$ & 160 & $40(25.0)$ & $0.73(0.63-0.82)$ & $0.215(0.005)$ & $0.052(0.600)$ \\
\hline \multicolumn{6}{|c|}{ Women Body mass index $\left(\mathrm{kg} / \mathrm{m}^{2}\right)$} \\
\hline Total & 755 & $101(13.4)$ & $0.75(0.70-0.81)$ & $0.197(<0.001)$ & $0.104(0.002)$ \\
\hline$<22.0$ & 308 & $10(3.2)$ & $0.74(0.62-0.87)$ & $0.149(0.008)$ & $0.055(0.334)$ \\
\hline $22.0-25.0$ & 263 & $26(9.9)$ & $0.71(0.60-0.82)$ & $0.250(<0.001)$ & $0.136(0.039)$ \\
\hline$<25.0$ & 571 & $36(6.3)$ & $0.74(0.65-0.82)$ & $0.194(<0.001)$ & $0.092(0.026)$ \\
\hline$\geq 25.0$ & 184 & 65 (35.3) & $0.68(0.60-0.76)$ & $0.231(0.001)$ & $0.176(0.019)$ \\
\hline
\end{tabular}

Multivariate-adjusted for confounding factors in Table 4. 
confounding variables, including directly measured insulin sensitivity and acute insulin response. ALT/AST ratio that includes information on at least two measures might have a more integrated explanation than single measures such as ALT or TG.

There are a number of possible mechanisms that can explain the association between the ALT/AST ratio and insulin resistance. Fat accumulation in the liver is characterized by several features of insulin resistance in normal weight and moderately overweight subjects, independent of BMI and intra-abdominal and overall obesity [32]. Increased liver fat content, a disorder that has detrimental effects on components of the metabolic syndrome, is known to be significantly correlated with these markers [33]. Nanji et al. [34] reported a significant correlation between ALT/AST ratio and the degree of fatty infiltration of the liver. Moreover, non-alcoholic fatty liver disease (NAFLD), which has recently been proposed as a feature of the metabolic syndrome [35], was also characterized by chronic elevations in liver transaminase levels, including ALT, AST, and GGT [36,37]. ALT/AST ratio and ALT per se along with the cut-off points might be reflecting NAFLD, but in this study, we have not evaluated ultrasound liver findings. Although, this study is of interest because liver transaminase markers, which are inexpensive and routinely collected in clinical settings, may provide a simple and accurate enhancement to models currently used to identify subjects with insulin resistance.

Some limitations of this study must be considered. First, the cross-sectional study design is limited in its ability to eliminate causal relationships between ALT/AST ratio and HOMA-IR. Second, our definition of HOMA-IR is based on a single assessment of FBS and IRI, which may introduce misclassification bias, although common to most epidemiological studies. However, random errors due to the fluctuations of laboratory measurements usually lead to a reduced estimate of the associated strength. Third, our study participants might include patients with subclinical liver diseases (i.e., chronic viral hepatitis, or drug-induced liver injury). These liver diseases are present in community-dwelling persons and are usually asymptomatic. Therefore the demographics and referral source may limit generalizability.

\section{Conclusions}

The present study demonstrated that ALT/AST ratio is associated with insulin resistance according to BMI in a general population. The ability to identify who is non-obese or overweight and who is insulin resistant could help health care professionals in bringing about lifestyle interventions. In that context, use of the cutoff-points of ALT/AST ratio described in this report is simple and useful. The present data documented that in non-obese Japanese adults ALT/AST ratio may be the best reliable marker of insulin resistance. Further prospective population-based studies are needed to investigate the changes in lipid metabolism by lifestyle interventions.

\section{Competing interests}

The authors declare that they have no competing interests.

\section{Authors' contributions}

$\mathrm{RK}, \mathrm{YT}$, and KK participated in the design of the study, performed the statistical analysis and drafted the manuscript. TK and AM contributed to acquisition of data and its interpretation. RK and MA contributed to conception and design of the statistical analysis. TM conceived of the study, participated in its design, coordination and helped to draft the manuscript. All authors read and approved the manuscript.

\section{Acknowledgements}

This work was supported in part by a grant-in-aid for Scientific Research from the Foundation for Development of Community (2012).

\section{Author details}

'Department of Community Medicine, Ehime University Graduate School of Medicine, Toon-city, Ehime, Japan. ${ }^{2}$ Department of Geriatric Medicine, Ehime University Graduate School of Medicine, Toon-city, Ehime, Japan. ${ }^{3}$ Center for Genomic Medicine, Kyoto University Graduate School of Medicine, Sakyo-ku, Kyoto 606-8501, Japan. ${ }^{4}$ Department of Internal Medicine, Seiyo Municipal Nomura Hospital, Seiyo-city, Ehime 797-1212, Japan.

Received: 9 August 2012 Accepted: 20 September 2012

Published: 1 October 2012

\section{References}

1. Gallagher EJ, Leroith D, Karnieli E: Insulin resistance in obesity as the underlying cause for the metabolic syndrome. Mt Sinai J Med 2010, 77:511-523.

2. DeFronzo RA, Ferrannini E: Insulin resistance: a multifaceted syndrome responsible for NIDDM, obesity, hypertension, dyslipidemia, and atherosclerotic cardiovascular disease. Diabetes Care 1991, 14:173-194.

3. Fontbonne AM, Eschwege EM: Insulin and cardiovascular disease: Paris prospective study. Diabetes Care 1991, 14:461-469.

4. Eckel RH, Grundy SM, Zimmet PZ: The metabolic syndrome. Lancet 2005 , 365:1415-1428.

5. Matthews DR, Hosker JP, Rudenski AS, Naylor BA, Treacher DF, Turner RC: Homeostasis model assessment: insulin resistance and beta-cell function from fasting plasma glucose and insulin concentrations in man. Diabetologia 1985, 28:412-419.

6. Meisinger C, Löwel H, Heier M, Schneider A, Thorand B, KORA Study Group: Serum gamma-glutamyltransferase and risk of type 2 diabetes mellitus in men and women from the general population. J Intern Med 2005, 258:527-535.

7. Wannamethee SG, Shaper AG, Lennon L, Whincup PH: Hepatic enzymes, the metabolic syndrome, and the risk of type 2 diabetes in older men. Diabetes Care 2005, 28:2913-2918.

8. Doi Y, Kubo M, Yonemoto K, Ninomiya T, Iwase M, Tanizaki Y, Shikata K, lida M, Kiyohara Y: Liver enzymes as a predictor for incident diabetes in a Japanese population: the Hisayama study. Obesity (Silver Spring) 2007, 15:1841-1850.

9. Monami M, Bardini G, Lamanna C, Pala L, Cresci B, Francesconi P, Buiatti E, Rotella CM, Mannucci E: Liver enzymes and risk of diabetes and cardiovascular disease: results of the Firenze Bagno a Ripoli (FIBAR) study. Metabolism 2008, 57:387-392.

10. Gao F, Pan JM, Hou XH, Fang QC, Lu HJ, Tang JL, Gu HL, Pan ZJ, Yao YH, Shen WZ, Jia WP: Liver enzyme concentrations are closely related to prediabetes: findings of the Shanghai Diabetes Study II (SHDS II). Biomed Environ Sci 2012, 25:30-37.

11. André $P$, Balkau B, Vol S, Charles MA, Eschwège E, DESIR Study Group: Gamma-glutamyltransferase activity and development of the metabolic syndrome (International Diabetes Federation Definition) in middle-aged men and women: Data from the Epidemiological Study on the Insulin Resistance Syndrome (DESIR) cohort. Diabetes Care 2007, 30:2355-2361.

12. Xu Y, Bi YF, Xu M, Huang Y, Lu WY, Gu YF, Ning G, Li XY: Cross-sectional and longitudinal association of serum alanine aminotransaminase and ${ }^{-}$ glutamyltransferase with metabolic syndrome in middle-aged and elderly Chinese people. J Diabetes 2011, 3:38-47. 
13. Steinvil A, Shapira I, Ben-Bassat OK, Cohen M, Vered Y, Berliner S, Rogowski O: The association of higher levels of within-normal-limits liver enzymes and the prevalence of the metabolic syndrome. Cardiovasc Diabetol 2010, 9:30.

14. Sookoian S, Pirola CJ: Alanine and aspartate aminotransferase and glutamine-cycling pathway: Their roles in pathogenesis of metabolic syndrome. World J Gastroenterol 2012, 18:3775-3781.

15. Vozarova B, Stefan N, Lindsay RS, Saremi A, Pratley RE, Bogardus C, Tataranni PA: High alanine aminotransferase is associated with decreased hepatic insulin sensitivity and predicts the development of type 2 diabetes. Diabetes 2002, 51:1889-1895.

16. Ortega E, Koska J, Salbe AD, Tataranni PA, Bunt JC: Serum gamma-glutamyl transpeptidase is a determinant of insulin resistance independently of adiposity in Pima Indian children. J Clin Endocrinol Metab 2006, 91:1419-1422.

17. Kawamoto R, Tabara Y, Kohara K, Miki T, Kusunoki T, Takayama S, Abe M, Katoh T, Ohtsuka N: High-sensitivity C-reactive protein and gammaglutamyl transferase levels are synergistically associated with metabolic syndrome in community-dwelling persons. Cardiovasc Diabetol 2010, 9:87.

18. Kawamoto R, Kohara K, Tabara Y, Miki T: An association between metabolic syndrome and the estimated glomerular filtration rate. Intern Med 2008, 47:1399-1406.

19. Friedewald WT, Levy RI, Fredrickson DS: Estimation of the concentration of low-density lipoprotein cholesterol in plasma, without use of the preparative ultracentrifuge. Clin Chem 1972, 18:499-502

20. Yeni-Komshian H, Carantoni M, Abbasi F, Reaven GM: Relationship between several surrogate estimates of insulin resistance and quantification of insulin-mediated glucose disposal in 490 healthy nondiabetic volunteers. Diabetes Care 2000, 23:171-175.

21. Taniguchi A, Fukushima M, Sakai M, Kataoka K, Miwa K, Nagata I, Doi K, Tokuyama K, Nakai Y: Insulin-sensitive and insulin-resistant variants in nonobese Japanese type 2 diabetic patients. The role of triglycerides in insulin resistance. Diabetes Care 1999, 22:2100-2101

22. Bonora E, Kiechl S, Willeit J, Oberhollenzer F, Egger G, Targher G, Alberiche M, Bonadonna RC, Muggeo M: Prevalence of insulin resistance in metabolic disorders: the Bruneck Study. Diabetes 1998, 47:1643-1649.

23. Wallace TM, Levy JC, Matthews DR: Use and abuse of HOMA modeling. Diabetes Care 2004, 27:1487-1495.

24. Kim-Dorner SJ, Deuster PA, Zeno SA, Remaley AT, Poth M: Should triglycerides and the triglycerides to high-density lipoprotein cholesterol ratio be used as surrogates for insulin resistance? Metabolism 2010, 59:299-304

25. Kannel WB, Vasan RS, Keyes MJ, Sullivan LM, Robins SJ: Usefulness of the triglyceride-high-density lipoprotein versus the cholesterol-high-density lipoprotein ratio for predicting insulin resistance and cardiometabolic risk (from the Framingham Offspring Cohort). Am J Cardiol 2008, 101:497-501.

26. Tamada M, Makita S, Abiko A, Naganuma Y, Nagai M, Nakamura M: Lowdensity lipoprotein cholesterol to high-density lipoprotein cholesterol ratio as a useful marker for early-stage carotid atherosclerosis. Metabolism 2010, 59:653-657

27. Kimm H, Lee SW, Lee HS, Shim KW, Cho CY, Yun JE, Jee SH: Association between lipid measures and metabolic syndrome, insulin resistance and adiponectin. - Usefulness of lipid ratios in Korean men and women. Circ J 2010, 74:931-937.

28. Kawamoto R, Tabara Y, Kohara K, Miki T, Kusunoki T, Takayama S, Abe M, Katoh T, Ohtsuka N: Relationships between lipid profiles and metabolic syndrome, insulin resistance and serum high molecular adiponectin in Japanese community-dwelling adults. Lipids Health Dis 2011, 10:79.

29. Ioannou GN, Weiss NS, Boyko EJ, Kahn SE, Lee SP: Contribution of metabolic factors to alanine aminotransferase activity in persons with other causes of liver disease. Gastroenterology 2005, 128:627-635.

30. Hanley AJ, Wagenknecht LE, Festa A, D'Agostino RB Jr, Haffner SM: Alanine aminotransferase and directly measured insulin sensitivity in a multiethnic cohort: the Insulin Resistance Atherosclerosis Study. Diabetes Care 2007, 30:1819-1827.

31. Homsanit M, Sanguankeo A, Upala S, Udol K: Abnormal liver enzymes in Thai patients with metabolic syndromes. J Med Assoc Thai 2012, 95:444-451.

32. Seppälä-Lindroos A, Vehkavaara S, Häkkinen AM, Goto T, Westerbacka J, Sovijärvi A, Halavaara J, Yki-Järvinen H: Fat accumulation in the liver is associated with defects in insulin suppression of glucose production and serum free fatty acids independent of obesity in normal men. $J$ Clin Endocrinol Metab 2002, 87:3023-3028.
33. Browning JD, Szczepaniak LS, Dobbins R, Nuremberg P, Horton JD, Cohen JC, Grundy SM, Hobbs HH: Prevalence of hepatic steatosis in an urban population in the United States: impact of ethnicity. Hepatology 2004 , 40:1387-1395.

34. Nanji AA, French SW, Freeman JB: Serum alanine aminotransferase to aspartate aminotransferase ratio and degree of fatty liver in morbidly obese patients. Enzyme 1986, 36:266-269.

35. Marchesini G, Brizi M, Bianchi G, Tomassetti S, Bugianesi E, Lenzi M, McCullough AJ, Natale S, Forlani G, Melchionda N: Nonalcoholic fatty liver disease: a feature of the metabolic syndrome. Diabetes 2001, 50:1844-1850.

36. Mulhall BP, Ong JP, Younossi ZM: Non-alcoholic fatty liver disease: an overview. J Gastroenterol Hepatol 2002, 17:1136-1143.

37. Schindhelm RK, Diamant M, Dekker JM, Tushuizen ME, Teerlink T, Heine RJ: Alanine aminotransferase as a marker of non-alcoholic fatty liver disease in relation to type 2 diabetes mellitus and cardiovascular disease. Diabetes Metab Res Rev 2006, 22:437-443.

\section{doi:10.1186/1475-2840-11-117}

Cite this article as: Kawamoto et al:: Alanine aminotransferase/aspartate aminotransferase ratio is the best surrogate marker for insulin resistance in non-obese Japanese adults. Cardiovascular Diabetology 2012 $11: 117$.

\section{Submit your next manuscript to BioMed Central and take full advantage of:}

- Convenient online submission

- Thorough peer review

- No space constraints or color figure charges

- Immediate publication on acceptance

- Inclusion in PubMed, CAS, Scopus and Google Scholar

- Research which is freely available for redistribution 